\title{
Comparative Analysis of the Level of Formation of Professional Reliability of Future and Active Teachers of Physical Education
}

\author{
O. O. Soltyk \\ Khmelnytskyi National University \\ Corresponding author. E-mail: Soltyk_sasha@i.ua
}

Paper received 11.10.18; Accepted for publication 16.10.18.

\begin{abstract}
https://doi.org/10.31174/SEND-PP2018-180VI74-13
\end{abstract}
\begin{abstract}
Annotation. Formation of professional reliability is viewed as a new trend in improvement of professional training of future teachers of physical education. Comparative analysis of the level of formation of professional competence of future and active teachers of physical education has been done. Availability of significant differences between indices of professional reliability with students and active teachers of physical education has been revealed. The most significant differences have been revealed by the indices that characterize faultlessness, efficiency, and self-devotion of professional reliability of future teachers of physical education. Primary trends of making an impact on the educational process with the purpose of formation of professional reliability of future teachers of physical culture have been pointed out.
\end{abstract}

Keywords: Professional reliability, teacher of physical education

Introduction. The problem of providing quality training of future teachers of physical education is one of the most important in present-day education. Successful tackling of educational tasks in youth's health protection, organization of motor activity, support of high level of development of motor skills, improvement of body's adaptation and functional reserves is primarily stipulated by the level of teacher's training, quality of formation of professional competences, teacher's individual qualities etc. Current state of human life characterized by decrease in youth's motor activity, deterioration of health caused by society mass informatization, all-round implementation of automated machines in various spheres of life etc. only increases the role and significance of profession of a teacher of physical education. At the same time, tackling the problem of professional training of future teachers of physical education must be based on existing realia taking into account present-day tendencies of higher education, include modern approaches and trends in improvement of quality of professional training. We consider formation of professional reliability of future teachers of physical education in the process of education in higher educational establishments to be one of the perspective trends in improvement of quality of professional training.

Brief survey of related references. Despite extensive use of the notion of reliability in various spheres of human life, in the sphere of education reliability remains littlestudied and insufficiently researched. Rare scientific papers do not give complete idea on the process of formation of professional reliability of future teachers. Profession of a teacher of physical education is even less studied.

Among popular papers, research by O. Osadchuk should be mentioned. In these papers, the author analyses teacher's professional reliability as an integral feature that comprises personal, subjective, and individual characteristics [2]. It is the combination of these features and use of mechanisms of self-regulation that help a teacher to successfully realize pedagogical functions under changing conditions of educational environment. D. Romanov proposes to view teacher's professional reliability through stability and resistance to burnout and other negative factors that influence professional activity [4].

Some researchers consider teacher's reliability to be a guarantee of gaining students and parents' trust [10]. Thus, they consider a teacher to be liable if he or she rarely comes late or misses classes. In other works, reliability along with responsibility is viewed as a component of teacher's professionalism. Characteristic features of reliability include consistent execution of professional tasks and duties; punctual and responsible work with papers etc. [6] Reliability is also related to high level teacher's efficiency that manifests itself in teacher's efforts to educate students more successfully and efficiently [8].

At the same time, it should be noted that the majority of foreign scientists primarily focus on teacher's assessment activity when studying teacher's reliability. Accordingly, teacher's reliability is characterized by how accurate a grade was given.

Thus, the author [5] emphasizes that it is inaccurate assessment that primarily causes decrease of teacher's reliability. Among factors that influence on assessment accuracy, not only sex, social and financial status, efforts and behavior have negative influence, but also frequent use of verbal sets of criteria that have certain degree of subjective interpretation.

Increasing trust to teacher's assessment, support of quality of teacher's solutions, and elaboration of efficient models of assessment at various stages of education are important in the sphere of education [1]. Other research papers [9] indicate that one of important ways to improve reliability of assessment in teacher's activity is finishing specific courses, learning how to administer test. This allows teachers to elaborate tests better that have higher level of reliability and probability of assessment.

To improve reliability of assessment, other researchers [3] propose expand testing field and formulate test questions more thoroughly. Use of clear instructions and standard administrative procedures promote better assessment.

Finishing talking about the issue of training educators, namely teachers of physical education, we must point out available interest of many researchers. However, the problem of formation of reliability in the process of training of teachers of physical training has not been adequately discussed.

The aim of our work is analyze the level of formation of professional reliability of active and future teachers of physical education who study in higher educational establishments. 
Materials and methods. Teachers of physical education from comprehensive schools and students with the respective major took part in the experiment. Analysis of class videos, analysis of teachers' documentation (lesson plan), timekeeping, pulse metrics, methods of mathematical statistics were used in the research along with pedagogical survey.

Results and discussion. Examination of the level of formation of professional reliability of future teachers of physical education was preceded by detailed analysis of the issue of reliability, formation of the concept of research, formulation of personal definition of the notion of reliability of a teacher of physical education. According to our view, professional reliability of future teachers of physical education is based on teacher's activity, which is characterized by faultlessness, efficiency and self-devotion under influence of changeable conditions professional and pedagogical environment throughout an entire lesson in physical education [7]. According to the definition, quantitative basis of professional reliability is characterized by six indices. Content of a lesson and deviation from lesson plan indicate on faultlessness. Motor and general densities of a lesson characterize efficiency of professional activity. Verbal and functional components indicate on self-devotion of a teacher during a lesson.

Deviation from a lesson plan was determined by viewing lesson videos and comparing it to the lesson plan. Differences in the use of various physical exercises, discrepancy of balancing arising during a lesson characterized faultlessness. We also considered boring lessons with use of monotonous physical exercises to be a fault. Accordingly, we estimated the index of lesson's content by the number of various physical exercises used by a teacher during a lesson.

To determine motor and general density of a lesson, we use the method of timekeeping. Calculating of time when students had no motor activity, figuring wasted time during a lesson allowed to determine the value of motor and gen- eral density of a lesson.

We defined self-devotion of a teacher of physical education by its two components - functional and verbal. Verbal self-devotion was characterized by the number of words uttered by a teacher during a lesson. Functional selfdevotion was defined with the help of pulse meter. With its help, we considered the difference between teacher's heart beats during a lesson and his/her pulse at rest. It is this difference that characterized functional value, that physiological waste, due to which a teacher was able to conduct a lesson.

According to our definition, a teacher of physical education who uses a variety of physical exercises, sticks to the lesson plan, gives students much important information during a lesson, being active, moving a lot, showing physical exercise, is professionally reliable. Moreover, a reliable teacher's lesson in physical education has good values of general density and appropriate level of motor density.

To check the level of formation of professional reliability, we have done a stating experiment, during which 244 students and 107 teachers of physical education took part. Apart from the values showing the level of manifestation of indices of professional reliability of active and future teachers of physical education, we focused on finding differences between students and teachers.

Comparison of these results and search for significant discrepancies sets necessary ground for further research of important aspects and components of professional training that must be influence more extensively with the purpose of formation of professional reliability of future teachers of physical education. To do it, we used on of the methods of mathematical statistics - Student's t-criterion. Capacity of Student's t-criterion to do run statistical check of two samples with regard to equality of average values enable us to compare the degree of discrepancy of various indices between students and teachers that characterize professional reliability. The results of calculations are presented in table 1.

Table. 1. Indices of discrepancies between the results of professional reliability of students and teachers of physical education by

\begin{tabular}{|c|c|c|c|c|c|c|c|}
\hline \multirow{3}{*}{ Index } & \multicolumn{6}{|c|}{ Student's t-criterion. } & \multirow{3}{*}{ t-criterion } \\
\hline & \multicolumn{3}{|c|}{ Students } & \multicolumn{3}{|c|}{ Teachers } & \\
\hline & $\mathrm{M}_{1}$ & $\sigma_{1}$ & $\mathrm{~N}_{1}$ & $\mathrm{M}_{2}$ & $\sigma_{2}$ & $\mathrm{~N}_{2}$ & \\
\hline Deviation from the lesson plan (\%) & 41,69 & 8,17 & 244 & 20,84 & 4,69 & 107 & 24,664 \\
\hline Lesson content (number of exercises) & 24,33 & 4,16 & 244 & 30,14 & 5,76 & 107 & 9,413 \\
\hline General density of the lesson (\%) & 73,78 & 8,37 & 244 & 84,10 & 8,11 & 107 & 10,734 \\
\hline Motor density of the lesson $(\%)$ & 29,16 & 9,48 & 244 & 61,26 & 8,11 & 107 & 30,47 \\
\hline Verbal self-devotion (number of words) & 1425,3 & 371 & 244 & 1803 & 309,8 & 107 & 9,214 \\
\hline Functional self-devotion ( $\triangle$ ЧCC) & 61 & 9,1 & 244 & 33,57 & 7,44 & 107 & 27,414 \\
\hline
\end{tabular}

Given the number of participants in the experiment, degree of freedom and limit values of Student's t-criterion $\left(t_{c r}=1,96\right.$ at $p=0,05 ; t_{c r}=2,58$ at $\left.p=0,01\right)$ have been defined.

As we see, the results show slight discrepancy of the level of formation of reliability of future and active teachers of physical education. By all indices that characterize professional reliability, we have revealed differences at the $\mathrm{d}=0.01$ level. Let us analyze them.

It should be emphasized that the most lagging aspect of professional reliability of future teachers of physical education is motor density of a lesson $(29.16 \%)$. Unlike students, teachers manage to build, organize, and conduct a lesson better than students do, in order for students to have dense motor activity. The students had most problems with sup- porting motor density while increasing the number of students during the lesson.

By other index, functional self-devotion, some significant differences have also been revealed. However, higher values are peculiar to students (61 blows in 1 minute). Compared to students, teachers of physical education distribute their motor activity more rationally. Selection of a good location during a lesson, decrease of switching places, and preference to explanation of educational material significantly limits functional waste of teachers.

Also, significant difference in the results of formation of professional reliability has been revealed by another index - deviation from the lesson plan $(41.69 \%$ with students; $20.84 \%$ with teachers). Given the fact that the results of 
deviation from lesson plan are influenced by many factors of educational process, we have extensive opportunities to improve the level of professional training with purpose of formation of professional reliability of a future teacher of physical education.

A slightly lower, compared to previous indices of professional reliability, but also significant, are other indices. Namely, students use smaller number of physical exercises during a lesson (24.33 exercises). At the same time, they use fewer words (1425.3), which indicates on a lag in the work of verbal apparatus. Lower values have also been revealed in general density of a lesson $(73.78 \%$ - students; $84.10 \%$ - teachers), which proves significant waste of time by students, when their students were engaged in motor activity and did not receive educational material.

The analysis of differences between formation of professional reliability of students and teachers allows to specify basic aspects and trends of professional training that must be focused on, and to introduce more significant changes to educational process. Such priority trends may include improvement of professional training with purpose of improvement of motor density during a lesson and decrease of deviation from the lesson plan. At the same time, given high level of functional self-devotion of future teachers of physical education, we assume there is no need to stimulate students for more motion actions and activity during a lesson. Moreover, students must try to avoid confusing motions that do not bear have educational information and are primarily caused by lack of experience, imperfect tech- nique, excessive anxiety etc.

Specific actions aimed at improvement of verbal selfdevotion that characterizes devotion must also be implemented in educational process of training of future teachers of physical education. Formation of the ability to bigger number of physical exercises by teachers of physical education during a lesson must have positive impact on the improvement of quality of professional training, which is reflected in lower number of faults, less wasted time, better organization of educational students' activity during lessons of physical education. As a result, it will help future teachers of physical education improve both level of professional reliability and quality of professional activity as a whole.

Conclusions. Comparative analysis of indices of the level of formation of professional reliability of future and active teachers of physical education allowed revealing significant discrepancies between indices that characterize reliability. The biggest lag with future teachers is related to indices of professional reliability of deviation from the lesson plan and to values of motor density. At the same time, index of functional self-devotion showed bigger workload of students' cardiovascular system.

The discrepancies of the formation of professional reliability of future teachers of physical education open up new trends that must be influenced during organization of educational process aimed at training of highly-qualified specialists.

\section{REFERENCES}

1. Catharine Parkes and Sarah Maughan. Methods for Ensuring Reliability of Teacher Assessments. Tuesday 2 June 2009, at The Royal Institute of British Architects.

2. Osadchuk O. L. (2007) Model of professional reliability of a teacher // Vyssheye obrazovaniye segodnya, № 5, 64-66.

3. Reliability Concerns for Classroom Summative Assessment (Blog), by Naiku. May 25, 2011, Available at: http://www.naiku.net/blog/reliability-concerns-for-classroomsummativeassessment. Retrieved March 7, 2012.

4. Romanov D.A. (2014) Teacher's professional reliability. Nauka. Tekhnika. Tekhnologii. № 2. 83-85.

5. Sandra Johnson. On the reliability of high-stakes teacher assessment. Journal Research Papers in Education. Volume 28, 2013 - Issue 1: The Reliability of Public Examinations.

6. Shon, Christopher K., "Teacher Professionalism." (2006). Faculty Publications and Presentations. Paper 46. http://digitalcommons.liberty.edu/educ_fac_pubs $/ 46$.

7. Soltyk O. Definition and Substantiation of Components, Criteria, and Indices of Professional Reliability of Teacher of Physical Education / O.O. Soltyk // Obriyi. - № 2(45), 2017. P. 74-80.

8. Teh Pei Ling, Zaidatol Akmaliah Lope Pihie, Soaib Asimirin, \& Foo Say Fooi. The Validity and Reliability of Teacher Efficacy Revisited in Malaysia Secondary Schools. / Journal of Studies in Education ISSN 2162-6952 2015, Vol. 5, No. 1. P. 27-35.

9. Validity and reliability of teacher-made tests: Case study of year 11 physics in Nyahururu District of Kenya. African Educational Research Journal Vol. 2(2), pp. 61-71, May 2014 ISSN: 2354-2160 Full Length Research Paper.

10. http://education.cu-portland.edu/blog/principalsoffice/reliability-teachers-trust/ 